\title{
Response to the letter to the Editor from Dr. Alexandre Rezende Vieira, entitled 'Prevalence of molar incisor hypomineralisation has a North-South gradient between Europe and North Africa'
}

\author{
N. A. Lygidakis ${ }^{1}$ (D)
}

Received: 21 July 2019 / Accepted: 23 July 2019 / Published online: 2 August 2019

c) European Academy of Paediatric Dentistry 2019

The letter comments on the recent EAPD paper "Prevalence of molar incisor hypomineralisation in a group of Egyptian children using the short form: a cross-sectional study" by Saber et al. (2018) and discusses one hypothesis regarding the different MIH prevalence in various areas and for this reason the Editor wants to sincerely thank the author of the letter Dr. Alexandre Rezende Vieira from the University of Pittsburgh, USA.

However, there are some additional data related to the subject that may question the approach leading to the statement that solely 'a complex genetic component is the reason certain individuals have MIH' as it is presented in the letter.

1. There are recent review papers analysing the global MIH prevalence (Jälevik 2010; Zhao et al. 2018; Schwendicke et al. 2018; Dave and Taylor 2018), not included in the letter, that may further help the discussion of MIH prevalence in certain areas.

2. Just one epidemiological study from Egypt (Saber et al. 2018) cannot by any means predict the absolute prevalence figures of any area, as it is clearly shown in all the above review papers. As it is indicated by Zhao et al. (2018), three at least studies may present a more stable figure for each country/area. In addition, studies from countries nearby to Egypt have shown greater prevalence figures (Jordan, Syria, Iraq, Iran and Saudi). Only Libya has shown lower figures (Schwendicke et al. 2018).

3. Although it is clear from previous (Lygidakis et al. 2008) and mainly from recent aetiology studies (Bussaneli et al. 2019) that a distinct genetic predisposition does exists, it is probably a scientific overestimation to state at

N. A. Lygidakis editor@eapd.eu

1 Editor in Chief, European Archives of Paediatric Dentistry, 2 Papadiamantopoulou Street, 11528 Athens, Greece present that 'a complex genetic component is the reason certain individuals have MIH', excluding other proven aetiological factors, i.e. systemic and environmental (Fatturi et al. 2019).

\section{References}

Bussaneli DG, Restrepo M, Fragelli CMB, et al. Genes regulating immune response and amelogenesis interact in increasing the susceptibility to molar-incisor hypomineralization. Caries Res. 2019;53:217-27.

Dave M, Taylor G. Global prevalence of molar incisor hypomineralisation. Evid Based Dent. 2018;19(3):78-9.

Fatturi AL, Wambier LM, Chibinski AC, et al. A systematic review and meta-analysis of systemic exposure associated with molar incisor hypomineralisation. Community Dent Oral Epidemiol. 2019. https ://doi.org/10.1111/cdoe.12467 [Epub ahead of print].

Jälevik B. Prevalence and diagnosis of molar-incisor-hypomineralisation (MIH): a systematic review. Eur Arch Paediatr Dent. 2010;11(2):59-64.

Lygidakis NA, Dimou G, Marinou D. Molar-incisor-hypomineralisation (MIH). A retrospective clinical study in Greek children. II. Possible medical aetiological factors. Eur Arch Paediatr Dent. 2008;9(4):207-17.

Saber F, Waly N, Moheb D. Prevalence of molar incisor hypomineralisation in a group of Egyptian children using the short form: a cross-sectional study. Eur Arch Paediatr Dent. 2018;19(5):337-45.

Schwendicke F, Elhennawy K, Reda S, et al. Global burden of molar incisor hypomineralisation. J Dent. 2018;68:10-8.

Zhao D, Dong B, Yu D, et al. The prevalence of molar incisor hypomineralization: evidence from 70 studies. Int J Paediatr Dent. 2018;28(2):170-9.

Publisher's Note Springer Nature remains neutral with regard to jurisdictional claims in published maps and institutional affiliations. 